EESTI NSV TEADUSTE AKADEEMIA TOIMETISED. XVIII KÖIDE KEEMIA * GEOLOOGIA. 1969, NR. 3

ИЗВЕСТИЯ АКАДЕМИИ НАУК ЭСТОНСКОЙ ССР. ТОМ ХVII ХИМИЯ * ГЕОЛОГИЯ. 1969. № 3

Д. КАЛЬО, П. ВИНГИСААР

\title{
О РАЗРЕЗЕ РАЙККЮЛАСКОГО ГОРИЗОНТА НА ЮЖНОЙ ОКРАИНЕ ЭСТОНИИ
}

Стратиграфическая схема силура Эстонии в последнее время постоянно совершенствовалась, уточнялись ее подразделения и их содержанне. В связи с ревизией объема юуруского горизонта (Нестор, Кала, 1968) была уточнена и нижняя граница райккюлаского горизонта, причем прежние низы горизона, так наз. каринуские или, частично, пускуские слои, были перенесены в нижележащий горизонт. Но окончательное упорядочение стратиграфии райккюлаского горизонта еще предстоит и поэтому полезно чпубликовать его характеристику по одному, на наш взгляд, очень интересному разрезу - по скважине Икла. Наряду с этим в данной статье рассматриваются и некоторые общие вопросы стратиграфии нижнего силура Сев. Прибалтики, связанные с излагаемым матерналом.

Структурно-гидрогеологическая скважина № 4 (Икла) пробурена в 1966 г. Гидрогеологической партией Управления геологии СМ ЭССР на юго-западной окраине Эстонии, в селе Икла на берегу Рижского залива.

Район Икла расположен в области наибольшего погружения фундамента в раннем силуре. В отличие от болєе западной части силурийского бассейна (например, разрез скв. Охесааре на юго-западе о-ва Саaремaа), где максимальное прогибание приходится на венлок, когда образовалась мощная толща глинисто-мергелевых пород (Аалоэ, Кальо, 1960), в данном районе оно началось еще в лландовери образованием мощной толщи известняков райккюлаского горизонта.

Мощность райккюлаского горизонта в скважине Икла 182,5 м (интервал 494,0-311,5 ; см. рис. 2), что в 3-4 раза превышает ранее известные ее значения. Породы здесь несколько более глинистые, но вместе с тем их основные литологические признаки выдерживаются и в данном разрезе: и здесь преобладают светлые желтоватые микрокристаллические известняки с прослоями желтовато- или буровато-серых горизонтально-полосчатых мергелей и глинистых известняков, легко от.тичающиеся как от перекрывающего. глинисто-мергелевого комплекса адавереского и яаниского горизонтов $(130,5$ м), так и от подстилающих пород юуруского горизонта - глинистых комковатых известняков, чередующихся с глинистыми мергелями $(31,0$ м). С последними, однако, райккюлаский горизонт тесно связан: нижняя его граница постепенная и проходит внутри седиментационного цикла. Вещественный состав пород райккюлаского и юуруского горизонтов показан на рис. 1. 
Ниже приводится краткая характеристика пород горизонта по отдельным литологическим комплексам снизу вверх (рис. 2).

I комплекс мощностью $16,0 \mathrm{M}$ образует вместе с юуруским горизонтом единый ритм, слагая более известковую часть последнего. Қомплекс сложен светлыми желтовато-серыми афанитовыми известняками, пятнисто доломитизированными, с большим количеством пиритизированных ходов червей, заполненных прозрачным крупнокристаллическим кальцитом. Текстура в нижней половине тонкослоистая, комковатая, обусловленная слоями зеленого мергеля, мощность которых уменьшается от 2 см внизу до $0,3-1,0$ c.⿲丿 у кровли. В комплексе встречены только единичные граптолиты и остракоды.

II комплекс $(18,6$ м) резко отличается от подстилающего, хотя признаков перерыва на границе нет. Представлен он чередующимися слоями известняков, нередко глинистых, и глинистых мергелей (до глин); последние преобладают. Нижняя часть комплекса (до глубины 471,5 м) сходна с породами юуруского горизонта: это породы зеленоватого цвета, с отчетливой комковатой текстурой (мощность слоев глинистого мергеля $3-5 \mathrm{~cm}$, известняков $1-3 \mathrm{~cm}$ ). Выше глубины 471,5 м текстура толсто- и среднеслоистая, слои горизонтальные, мощность их до $10-30$ см у глинистых темно-зеленых мергелей и 5 см-у серых полуафанитовых известняков. В первых встречаются тонкие прослойки буровато-серого глинистого сланца. В этом комплексе весьма редко встречаются брахиоподы и граптолиты.

III комплекс $(61,9$ м) вместе с нижележащими глинистыми слоями образует второй ритм седиментации. Нижняя граница комплекса довольно постепенная, в нижних слоях его прослеживаются еще относительно мощные прослои зеленого мергеля $(2-3$ см), сменяющиеся выше тонкими буроцветными. Комплекс, несмотря на большую мощность, литологически довольно однородный и представлен светлыми желтоватосерыми среднеслоистыми афанитовыми известняками с ровными, реже волнистыми прослоями серого и бурого мергеля. Часто известняки слабо-глинистые, почти всегда с полосчатой микротекстурой.

В нижней части комплекса (до глубины 439 м) границы чередующихся слоев мергелей и известняков очень резкие, выше чередование симметричное. До глубины 420 м в известняках наблюдаются прослойки известнякового доломита, внешне мало отличающиеся от первых. Мергелевые слои всегда четко обособлены, мощность их обычно $1-2$ см.

Для всего комплекса характерно обилие граптолитов, сосредоточенных на сланцеватых плоскостях напластования мергелей. Остатки других организмов не обнаружены, не считая находок некоторых строфоменид в базальных слоях.

IV комплекс $(21,8$ м), представляющий собой трансгрессивную часть следующего ритма, сложен чередующимися зеленовато-серым глинистым 


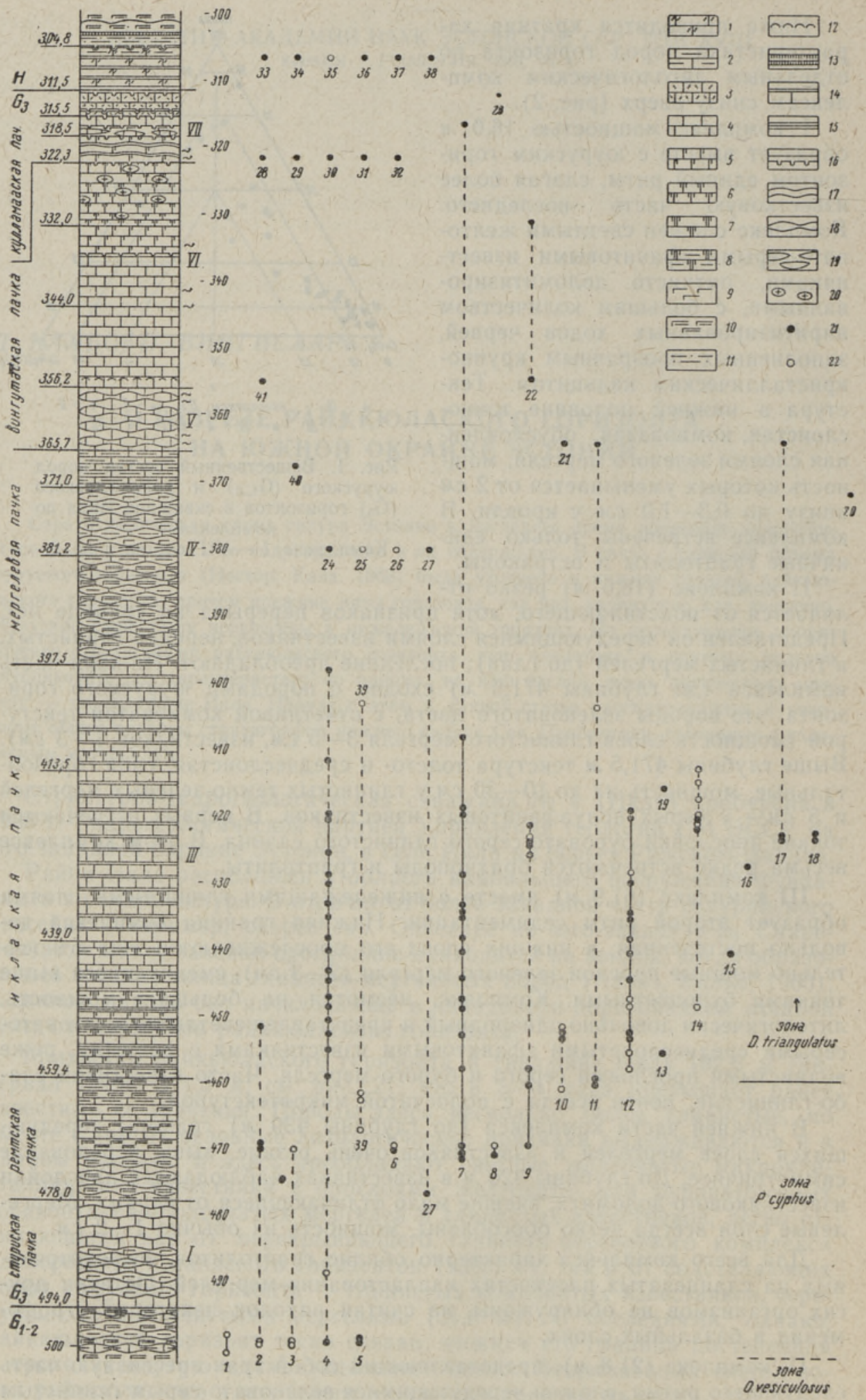


известняком и зеленым глинистым мергелем. Текстура тонкослоистая, комковатая, слои глинистого мергеля преобладают. В верхней части комплекса (с глубины 371 м) залегает тонко-горизонтальнослоистый светлый глинистый известняк, чередующийся с такими же слоями (12 cм) темного, зеленовато-серого мергеля. В породах IV комплекса встречаются довольно часто брахиоподы, главным образом тонкостенные строфомениды.

Залегающий выше $\mathrm{V}$ комплекс $(9,5$ м), связанный с граничащими отложениями постепенными переходами, представлен своеобразным тонкослоистым комковатым афанитовым известняком. Расположенные в буровато-сером полосчатом мергеле комки известняка диаметром 1 см всегда содержат в центре гнездо, обычно трубкообразное, заполненное прозрачным кристаллическим кальцитом.

VI комплекс $(33,9$ м) сложен однородными желтовато-серыми афанитовыми и полуафанитовыми известняками с горизонтальной, реже волнистой средней слоистостью, содержащими в интервале $344,0-332,0$ м много пиритизированных ходов илоедов. Слоистость известнякам придают слойки буровато-серого, выше зеленовато-серого мергеля мощностью от $1-2$ см до $1-2$ мм. В верхней части известняки немного доломитизированы и содержат диагенетические конкреции кремня диаметром до $5 \mathrm{cM}$.

Комплекс беден фауной; лишь у основания найден слой (10 cм) ракушечника из Stricklandia lens (Sow.) и там же- несколько тонких (1 cM) слойков крупнодетритового известняка.

Верхняя граница комплекса литологически резкая и выражена пиритизированной поверхностью перерыва.

Рис. 2. Распространение граптолитов, остракод и брахиопод в разрезе райккюлаского горизонта в скважине Икла.

Легенда литологической колонки: 1 - известняк мелкодетритистый шламовый; 2 известняк глинистый; 3 - известняк микрокристаллический шламовый; 4 - известняк афанитовый и полуафанитовый; 5 - то же доломитистый; 6 - то же доломитовый; 7 - доломит известковый; 8 - то же глинистый; 9 - мергель; 10 - то же глинистый; 11 - глина известковая; 12 - биоморфный слой; 13 - слой метабентонита; 14 - чередование известняков с мергелем; 15 - то же со сланцеватым мергелем; 16 - горизонтальнослоистая текстура и поверхность перерыва; 17 - волнисто-слоистая текстура; 18 - комковатая текстура; 19 - линзовидная текстура; 20 - конкреции кремня; 21 - вид определен точно; 22 - вид определен как conformis или affinis.

Распространение характерных представителей фауны, Грапт ол и ты:

1 - Paraclimacograptus aff. innotatus (Nich.); 2 - Pŕibylograptus sandersoni (Lapw.) 3 - P. incommodus (Törnq.); 4 - Rhaphidograptus toernquisti (E. \& W.);5-Dimorpho graptus confertus (Nich.); 6 - Climacograptus rectangularis M'Coy; 7 - Pseudoclimacograptus hughesi (Nich.); 8 - Pernerograptus revolutus revolutus (Kurck); 9 - Glyptograptus tamariseus Nich.; 10 - Přibylograptus atavus (Jones); 11 - Pristiograptus sp. nov., aff. gregarius (Lapw.); 12 - Demirastrites triangulatus (Harkn.); 13 - Petalograptus sp., $14-$ Pristiograptus gregarius (Lapw.); $15-$ Campograptus elongatus (Törnq.); 16 - Climacograptus scalaris His.; 17 - Monograptus gemmatus (Barr.); $18-M$. intermedius (Carr.); 19 - Demirastrites triangulatus raitzhainiensis Eisel; 20 - Campograptus communis (Lapw.); 21 - Petalograptus minor Elles; 22 - Rhadinograptus jurgensonae Obut; 23 - Climacograptus sp.

O ст ракоды: 24 - Polyzygia estonica Neck.; $25-$ Microcheilinella cf. lubrica (Stumb.); 26 - Bythocypris cf. diffusa Stumb.; 27 - Altha modesta Neck.; 28 - Craspedobolbina permira Sarv; 29 - Bolbibollia estona Sarv; 30 - Aitilia senecta Sarv; 31 - Neoprimitiella litvaensis (Neck.); 32 - Bythocyproidea sarvi Neck.; 33 - Leperditella gregaria Sarv; 34 - Arcuaria triangulata Neck.; 35 - Silenis cf. subtriangularis Neck; 36 - Rectella aequalis Neck.; $37-$ Microcheilinella acutafinis (Neck.); $38-$ M. semibulbosa (Neck.).

Б рахи оподы: 39 - Glassia cf. obovatā (Sow.); 40 - Atrypa hedei Struve: 41 Stricklandia lens (Sow.) 
IV-VI комплексы слагают третий седиментационный ритм, характеризующийся, подобно двум нижним, довольно мощными и однородными литологическими комплексами, сменяющими друг друга нормально, без признаков перерыва. В качестве регрессивной части с некоторой условностью сюда же можно включить VII комплекс.

Верхи райккюлаского горизонта литологически более пестрые, поэтому в следующий комплекс объединены довольно маломощные разнообразные слои, разграниченные поверхностями перерыва.

VII комплекс $(10,8$ м) начинается синевато-серым (из-за обилия пиритизированных ходов) микрокристаллическим копролитовым известняком, чередующимся с темно-серым глинистым мергелем $(3,8$ м). Текстура тонкослоистая, комковатая. В этих слоях встречаются поверхности перерыва. Выше следует палевый полуафанитовый известняк с тонкой линзовидной слоистостью $(1,5 \mathrm{M})$. Постепенно эти слои переходят г. среднеслоистый плотный светло-палевый афанитовый известняк с двумя прослойками $(2 \mathrm{~cm})$ крупнодетритового ругозово-мшанково-криноидного известняка $(1,4$ м). Верхняя часть комплекса (4 $M)$ представлена желтовато-серым среднеслоистым микрокристаллическим детритистым известняком. Из фауны встречены строматопороидеи, табуляты, граптолиты.

В отличие от описанных слоев, низы адавереского горизонта мощностью $6,7 \boldsymbol{M}$ (интервал $311,5-304,8$ м) имеют трансгрессивный характер и представляют собой чередование светло-серых мелкодетритисто-шламовых известняков и темно-серых, содержащих детрит мергелей на общем фоне увеличения глинистости снизу вверх. В кровле комплекса - слой $(0,4$ м) зеленовато-серого тонкослоистого глинистого известняка, изобилующего лимонитизированными ходами и содержащего не менее семи лимонитизированных поверхностей перерыва. Выше разрез адавереского и яаниского горизонтов представлен мощным комплексом глинистых мергелей.

Литостратиграфическое расчленение райккюлаского горизонта в скважине Икла и его сопоставление с другими разрезами производятся сравнительно легко, поскольку, как было уже сказано, по литологическому характеру разрез, несмотря на большие мощности, в принципе мало отличается от соответствующих разрезов Средней Эстонии.

I и II комплексы соответствуют выделенным впервые на территории Латвии стуриской и ремтской пачкам (Гайлите, Рыбникова, Ульст, 1967). В разрезе Икла эти пачки почти ничем не отличаются от их типовых разрезов. Горизонтальнослоистые афанитовые и полуафанитовые известняки, чередующиеся ритмично с мергелями и представляющие III комплекс, не имеют в Эстонии себе подобных, за исключением разрезов сравнительно близко расположенных скважин Абья и Хольдре. Наиболее типичны эти породы в настоящем разрезе, где они к тому же хорошо охарактеризованы большим количеством граптолитов.

Вышесказанное позволяет считать III комплекс самостоятельным литостратиграфическим подразделением, для которого здесь предлагается название «иклаская пачка».

IV комплекс сходен с бо́льшей частью разреза райккюлаского горизонта скважины Охесааре. Его также целесообразно выделить в качестве самостоятельного литостратиграфического подразделения; в настоящей статье мы называем данный комплекс просто мергелевой пачкой. Вышележащая афанитовая толща (V-VI комплексы) является, вероятно, несколько видоизмененным аналогом вингутаской пачки северных разрезов (см. Юргенсон, 1966). По сравнению с разрезом сква- 
жины Пярну в Икла афанитовые и полуафанитовые породы вингутаской пачки содержат больше глинистого материала как в самой породе, так и в внде прослоев. Последний, VII комплекс, в породах которого появляется детрит, можно с большой вероятностью рассматривать как аналог кулламааской пачки.

Нижняя граница райккюлаского горизонта проводится нами в разрезе скважины Икла на глубине 494,0 м (по подошве афанитовых известняков стуриской пачки). Основным критерием при этом служит резкая смена литологического характера отложений - зеленые глинистые мергели с прослоями комковатых известняков на этом уровне заменяются светлыми тонкослоистыми комковатыми афанитовыми известняками. Резкость границы и ее выдержанность (аналогичная литологическая смена прослеживается на большой территории) являются удобными отличительными признаками для проведения границы горизонта. Этими признаками в настоящее время и пользуются, хотя ряд причин заставляет усомниться в синхронности принятой границы. Во-первых, в северных и западных разрезах (скв. Пярну, Сурвакюла, Эйамаа, Охесааре и др.) в пределах райккюлаского горизонта прослеживаются только два седиментационных ритма, а в Икла прибавляется внизу еще один, вернее его известковая верхняя часть. Последняя, как можно предполагать, образовалась, вероятно, раньше афанитовых известняков вингутаской пачки северных разрезов. Отсутствие признаков перерыва в основании стуриской пачки, в то время когда в более северных районах наблюдаются, как правило, поверхности перерыва, также говорит о возможном выпадении из разреза некоторых пограничных слоев. Кроме того, логичнее было бы провести границу горизонтов не внутри ритма, а между ними. Во-вторых, вызывают сомнение некоторые палеонтологические данные. Так, в стуриской пачке встречены, кроме редких Climacograpius sp. и Rhaphidograptus cf. toernquisti (E. \& W.), остракоды Microcheilinella sp. sp., Rectella sp., Primitiella ? sp., Neoprimitiella sp., которые из-за плохой сохранности не могут быть точно определены, но, по заключению Л. Сарва, более сходны с остракодами юуруского горизонта.

В ремтской пачке состав фаунистического комплекса несколько изменяется - здесь больше граптолитов (рис. 2), часть которых была распространена уже ниже, и появляются некоторые новые остракоды Altha modesta Neck., Silenis sp., Primitiella ? sp. п., трилобиты Acernaspis sp. п. с (по данным Р. П. Мянниль; находки с глубины 461,4 и 472,8 м). Первая и последняя из перечисленных форм обыкновенно встречаются в райккюласком горизонте, а остальные более характерны для юуруского горизонта или же ничего определенного не говорят.

Некоторое изменение фаунистического комплекса и начало нового ритма седиментации указывают на возможность проведения нижней границы райккюлаского горизонта по подошве ремтской пачки. Но так как по граптолитам стуриская и ремтская пачки, вместе взятые, почти совпадают с зоной Pristiograptus cyphus (ее нижняя граница проходит немного ниже подошвы стуриской пачки, примерно на глубине $500 \boldsymbol{m}$; рис. 2), то возможен и третий вариант проведения нижней границы райккюлаского горизонта - по подошве иклаской пачки, т. е. по подошве зоны Demirastrites triangulatus. Последний вариант удобен в том смысле, что указанная граница совпадает с границей нижнего и среднего лландовери, принятой в СССР (Никифорова, Обут, 1965).

Из сказанного возникает вопрос: с каким из названных уровней синхронна нижняя граница райккюлаского горизонта в Средней Эстонии? Данные о распространении граптолитов в разрезах скважин Выхма, Қи- 
рикукюла, Курси, Охесааре, Отепя, Пярну, Сурвакюла и др. показывают, хотя и не очень четко, что подошва райккюлаского горизонта в этом районе находится на уровне зоны Pristiograptus cyphus (Кальо, 1967). Следовательно, находящиеся в пределах одной и той же зоны подошвы стуриской и ремтской пачек могут быть грубо (с ошибкой примерно на ползоны) одновозрастны с нижней границей на севере. Учитывая также данные Л. Гайлите, М. Рыбниковой и Р. Ульст (1967) по латвийским скважинам, мы видим, что резкое изменение характера осадконакопления происходит почти одновременно на сравнительно большой территории и поэтому, несмотря на высказанные выше сомнения, указывающие на бо́льшую сложность в деталях, нижнюю границу вполне можно провести по подошве афанитовых известняков, расположенной на уровне низов зоны Pristiograptus cyphus. K северу эта граница может незначительно повыситься во времени.

Большой интерес в разрезе скв. Икла представляет зональная стратиграфия по граптолитам.

Верхняя граница зоны Orthograptus vesiculosus проведена условно на глубине 500 м. Ниже этого уровня встречен только Paraclimacograptus aff. innotatus (Nich.), а выше наряду с типичным представителем зоны O. vesiculosus - Dimorphograptus confertus (Nich.) - встречаются и пржибылограпты (рис.2), указывающие на зону Pristiograptus cyphus. Так как Dimorphograptus confertus (Nich.) найден А. Обутом и P. Coболевской (1966) в зоне $P$. cyphus, то можно думать, что уровень этих находок является низами зоны $P$. cyphus.

Нижняя граница зоны Demirastrites triangulatus фиксируется хорошо. Интересно отметить, что в самых нижних слоях этой зоны, может быть даже до появления D. triangulatus, встречаются весьма многочисленные Pristiograptus aff. gregarius (Lapw.) (рис. 2). Это, вероятно, новый пристиограпт, очень похожий на $P$. gregarius, но имеющий постоянно более редко расположенные теки - 8 тек на 10 мм. Редкие находки этой формы сделаны и выше этих слоев.

Выше по разрезу появляются виды (рис. 2), встречающиеся и в следующей зоне - Demirastrites convolutus, но бесспорных представителей этой зоны там пока не найдено.

По распространению найденных форм можно заключить, что в скважине Икла мергелевая пачка и низы вингутаской пачки находятся примерно на уровне верхней части широкой зоны Pristiograptus gregarius. Следовательно, в Икла, так же как и в северных скважинах, слои с Rhadinograptus jurgensonae Obus составляют верхи среднего лландовери.

Верхняя граница райккюлаского горизонта в скважине Икла достаточно четко проводится по остракодам (рис. 2).

Таким образом, райккюлаский горизонт на юге Эстонии охватывает среднюю, наиболее карбонатную часть разреза лландовери, расчленяется на определенные литостратиграфические пачки и имеет достаточно четкие биостратиграфические границы.

\section{Л ИТ Е Р АТ У РА}

А а лоэ А., Кальо Д. 1962. Краткий обзор силурийских отложений в скважине Охеcaаре (о-в Сааремаа). Тр. Ин-та геол. АН ЭССР, 10.

Гайлите Л. К., Р ыб н и о ва М. В., У льст Р. Ж. 1967. Стратиграфия, фауна и условия образования силурийских пород Средней Прибалтики. Рига, «Зннатне».

К аль о Д. 1967. О возрасте нижних горизонтов силура Эстонии. Изв. АН ЭССР, Хим. Геол., 16. № 1. 
Н ест о р Х. Э., К а ла Э. А. 1968. Ревизия стратиграфии низов силура Северной Прибалтики. В сб.: Стратиграфия нижнего палеозоя Прибалтики. Вильнюс.

Н и к и фо р о в а О. И., О б у т А. М. 1965. Силурийская система. Стратиграфия СССР. М., «Недра».

О бу т А. М., Соболе в к а я Р. Ф. 1966. Граптолиты раннего силура в Казахстане. М., «Наука».

Юргенсон Э. А. 1956. Литология лландоверийских отложений Эстонии. Институт геологии Академин наук Эстонской ССР. Таллин.

$\begin{array}{cc}\text { Ннститут геологии } & \text { Поступила в редакцию } \\ \text { Академии наук Эстонской CCP } & 27 / V I I I ~ 1968 \\ \text { Управление геологии СМ ЭССР }\end{array}$

\section{KALJO, P. VINGISAAR}

\section{RAIKKULA LADEME LÄBILŌIKEST EESTI LOUNAPIIRIL}

Kirjeldatakse Ikla puursüdamiku läbilõiget, milles raikküla lademe osas eristatakse sturi, remte, ikla (esmakordselt), merglite, vinguta ja kullamaa kihistik. Hoolimata umbes kolm korda suuremast paksusest $(182,5 \mathrm{~m})$ on Iklas lademe litoloogiline ilme küllaltki sarnane põhjapoolsetel aladel esinevale. Läbilōikes on esindatud Orthograptus vesiculosus'e, Pristiograptus cyphus'e ja P. gregarius'e tsooni (sensu lato) graptoliidid. Lademe alumise piirina vaadeldakse litoloogiliselt hästi markeeritud ja praktiliselt $P$. cyphus'e tsooni alguse tasemel asuvat sturi kihistiku alumist piiri. Samal ajal osutavad mitmed asjaolud võimalusele alustada raikküla ladet mōnevõrra kōrgemalt.

\section{KALJO, P. VINGISAAR}

\section{ON THE SEQUENCE OF THE RAIKKULA STAGE IN SOUTHERNMOST ESTONIA}

The authors present a description of the section of the Raikküla Stage in the structuralhydrogeological borehole No. 4, in the village of Ikla on the Baltic Sea, on the border of the Estonian and Latvian SSR. In the lithological column (Fig. 2) the following legends have been used: 1 - muddy fine-detritic limestone; $2-$ clayey limestone; 3 - fine-crystalline muddy limestone; 4 - aphanitic and semiaphanitic limestone; 5 - dolomitic limestone; 6 - dolomite-limestone; 7 - calcareous dolomite; 8 - clayey dolomite; 9 - marl; 10 - clayey marl; 11 - calcareous clay; 12 - biomorphous layer; 13 - metabentonitic layer; 14 - intercalation of limestones and marl; 15 - intercalation of limestones with shales; $16-$ horizontal-layered structure and discontinuity surface; 17 - wavy-layered structure; 18 - nodular structure; 19 - lenticular structure; 20 - silliceous concretion; 21 - precisely defined species; 22 - species defined as conformis or affinis. The denominations of the found graptolites, ostracodes and brachiopods are presented in the Russian text of Fig. 2. Figure 1 shows the composition of the rocks of the Juuru $\left(\mathrm{G}_{1_{-2}}\right)$ and Raikküla $\left(\mathrm{G}_{3}\right)$ Stages in the borehole of Ikla. The complexes I-VII are in accordance with Fig. 2.

In comparison with the sections situated in the northerly direction, the Raikküla Stage in the borehole of Ikla is about three times thicker, whereas the lithological character of the stage is in general the same. The following members may be defined (from bottom to top): the Sturi, Remte, Ikla, marly, Vinguta and Kullamaa members. Of those, the Ikla member has been defined for the first time, its distribution in Estonia is limited to the southernmost part of the country, only. The lower boundary of the stage passes along the lithologically clearly defined base of the Sturi member, i. e. near the base of the Pristiograptus cyphus zone. Some considerations are also presented, which point to the possibility of drawing this boundary along the base of the Remte or Ikla members. In the lowermost parts of the $P$. cyphus zone, some representatives of the Orthograptus vesiculosus zone are stated - Dimorphograptus confertus (Nich.) (Fig. 2). Besides the above-mentioned, the Demirastrites triangulatus zone is also well respresented in the borehole of Ikla; the lowermost part of that zone is characterized by the presence of a probably new species - Pristiograptus aff. gregarius (Lapw.). The marly member is probably distributed at the level of the upper part of the Pristiograptus gregarius zone sensu lato, and the beds with Rhadinograptus jurgensonae Obut form the upper part of the Middle Llandovery. Together with the latter the high form of Stricklandia lens is also distributed. 